\title{
O consumo da política na Revista da Semana entre 1910 e 1914: a sátira gráfica e o colunismo social como componentes de um mesmo projeto afetivo-editorial
} The consumption of politics in Revista da Semana between 1910 and 1914: graphic satire and social columnism as components of the same affectiveeditorial project

Eliza Bachega Casadei

Docente do Programa de Pós-graduação em Comunicação e Práticas de Consumo da Escola Superior de Propaganda e Marketing, Brasil. Doutora em Ciências da Comunicação pela Escola de Comunicações e Artes da Universidade de São Paulo, Brasil. E-mail: elizacasadei@yahoo.com.br

\begin{abstract}
Resumo:
A partir do mapeamento das características composicionais da produção imagética na área de política da Revista da Semana, no período entre 1910 e 1914, o objetivo do presente artigo é estudar a estruturação do pathos político mobilizado pela publicação a partir da mediação dos afetos em seu projeto editorial. A temática da política ao longo desse período esteve estruturada como colunismo social e como sátira gráfica, compondo um mesmo projeto afetivo-editorial. O objetivo do artigo é estudar as estratégias a partir das quais o jornalismo da Revista da Semana mobilizou mecanismos de convocação na mediação de cadeias de afetos que validam formas de vida e o delineamento dos possíveis discursivos no campo da política.
\end{abstract}

\section{Palavras-chave:}

Política; Afetos; Revista da Semana; 1910-1914.

\begin{abstract}
:
Mapping the compositional characteristics of the imagery production in the area of politics in Revista da Semana in the period between 1910 and 1914, the objective of this article is to study the structuring of the political pathos mobilized by the publication, from the mediation of the affections in its editorial project. The theme of policy over that period was structured as social columns and as a graphic satire, composing one affective-editorial project. The objective of this article is to study the strategies from which Revista da Semana journalism has mobilized convocation mechanisms in the mediation of affections that validate life forms and the delineation of the field of discursive possibilities in politics.
\end{abstract}

Keywords:

Policy; Affections; Revista da Semana; 1910-1914. 


\section{Introdução}

A estruturação imagética da Revista da Semana variou bastante em termos de sua concepção nos primeiros anos de existência da publicação, revelando experimentações diversas no seu projeto editorial. Especificamente no período que se estende do final da década de 1900 até meados de 1914, a Revista da Semana passou a dar uma ênfase acentuada para os assuntos políticos - que estavam estruturados imageticamente a partir de dois eixos: a saber, (1) como colunismo social e (2) como sátira gráfica. Embora a ligação entre esses dois eixos não seja óbvia, é possível observar que eles compõem um mesmo projeto afetivo-editorial. $\mathrm{O}$ objetivo do presente artigo é estudar as características composicionais da produção imagética da Revista da Semana neste período com o intuito de mapear a estruturação do pathos político mobilizado pela publicação.

Tal como pontuado por Safatle (2016, p. 15), compreender o campo social implica em abordar também o conjunto de emoções que são mobilizadas nesse campo, explicitando "seus modos de construção, seus circuitos de afetos com regimes extensivos de implicação, assim como compreender o modelo de individualização que" tais afetos produzem, "a forma como ele nos implica". É o afeto implicado que, em última medida, determina a aquiescência às normas sociais e à adesão a certos valores compartilhados. O jornalismo participa da mediação de cadeias de afetos que validam formas de vida e o delineamento do campo dos possíveis discursivos. Nesse artigo, estudaremos as estratégias a partir das quais tais afetos foram mobilizados na Revista da Semana em sua cobertura política a partir das técnicas de composição postas nas imagens. Tais afetos estão correlacionados a um projeto afetivo-editorial mais amplo da publicação em seus primeiros anos.

Para isso, em um primeiro momento, iremos esmiuçar o conceito de projeto afetivo-editorial. Na sequência, mapearemos as características composicionais das imagens políticas da Revista da Semana no período a partir (1) dos enquadramentos utilizados; (2) dos actantes e dos atores sociais mobilizados e (3) da mise-en-scène exposta. A partir disso, será possível estudar os modos como tais características materializam estratégias de mediação do pathos político e as estratégias utilizadas pela publicação nesse sentido. 


\section{As características composicionais da política na Revista da Semana}

O conceito de projeto afetivo-editorial pode ser melhor delineado levando-se em consideração, tal como Lordon (2015), que as afeições não são características intrínsecas ao sujeito. "Existem, sim, indivíduos e eles experimentam afetos, mas esses afetos não são senão o efeito das estruturas nas quais os indivíduos estão mergulhados" (LORDON, 2015, p. 10). Para o autor, "existem estruturas, e nas estruturas existem homens passionais; em primeira instância, os homens são movidos por suas paixões; em última análise, suas paixões são amplamente determinadas pelas estruturas". Para o autor, os próprios regimes de acumulação do capitalismo, nesse sentido, se exprimem em certos desejos e afetos ou, de forma mais precisa, cada estruturação de acumulação de capital tem uma espécie de estrutura dual composta por um complexo de sentimentos que o sustenta e o reproduz.

Para aprofundar essa ideia, Lordon recorre à ideia espinosiana de conatus, entendida como uma energia genérica cuja determinação é dada por afecções exteriores, inscritas em estruturas sociais, que a orientam concretamente em direção a um objeto. A energia do conatus, dessa forma, investe em determinados objetos por meio de afecções que estão inscritas em sistemas mais amplos e são socialmente determinadas. "Ela só toma forma escorrendo pelas estruturas sociais, nas formas institucionais e nas relações sociais, que lhe oferecem suas condições concretas de exercício e, por isso mesmo, configuram seus investimentos possíveis, determinando-a para alguma coisa - salvação, glória, fortuna (ou qualquer outro objeto a almejar)". Para citar alguns exemplos do que o autor chama de formações macrossociais do desejo, é possível evocar "as estruturas do capitalismo, em suas configurações históricas sucessivas, que dão aos homens da era capitalista os objetos em que suas energias conativas se investirão" como "os movimentos dos corpos assalariados, primeiramente, para lutar contra o perecimento, depois, pelas alegrias extrínsecas do consumo mercantil e, enfim, pelas alegrias intrínsecas da 'vida preenchida' ou 'da vocação realizada no e pelo trabalho" (LORDON, 2015, p. 74). Estruturas sociais anteriores teriam oferecido outras estruturações duais de emoções, desejos e recompensas, tal como a glória do combate, as esperanças de salvação e o desejo por magnitude para um grupo social específico no regime feudal. Tais 
estruturações das emoções e do desejo podem ser mapeadas desde uma escala macrossocial (concernentes ao regime de acumulação capitalista, por exemplo) até circunscrições bem menores, específicas de grupos ou instituições sociais.

Trata-se, como posto por Lordon, de uma releitura da noção de campo, de Bourdieu, que não são mais do que realizações concretas de lugares de desejos, imaginários e afetos organizados de forma estrutural e compartilhados socialmente. As instituições, aqui, como é o caso da própria imprensa, são compreendidas como os mecanismos por meio dos quais o conatus intransitivo se torna transitivo, ou seja, direcionado a um objeto a partir de uma afeição. São as instituições que dão forma às emoções amorfas e, consequentemente, permitem certos tipos de afetos enquanto barram outros, fornecendo a partilha dos desejos validados e dos não legitimados. Cada instituição tem uma circunscrição e uma extensão próprias (o campo científico só afeta aos cientistas, por exemplo) e, por isso, diferentes capacidades de afecção. Em conjunto, as diversas instituições que atuam sobre um sujeito, em diferentes graus de influência e impacto, irão compor um complexo de afetos que irão se manifestar de maneiras diferentes em cada indivíduo - mesmo que compostas a partir de uma base comum para um determinado grupo.

Assim, "no plano de fundo de toda interação empregado/empregador particular, há justamente a integralidade das estruturas da relação salarial, com toda profundidade de seu desenvolvimento histórico", porém, "todo esse desenvolvimento só se realiza na localidade das múltiplas interações concretas concebidas como encontros de objetos determinados" (LORDON, 2015, p. 78). Forma-se, assim, uma "aritmética das composições afetivas".

É esse jogo entre as diversas estruturações sociais da emoção que fornecem, para Lordon, o fundamento da mudança social. Crises institucionais são marcadas, justamente, por mudanças nos afetos, que podem levar a necessidade de reconfiguração dessas mesmas instituições ou, até mesmo, revoluções mais bruscas no sistema como um todo. "Afinal, qualquer instituição não passa de uma estabilização temporária de certa relação de potências", posto que "o imperium da instituição nada mais é que o afeto comum que ela consegue produzir para determinar que os indivíduos vivam de acordo com sua norma”. Os sistemas são incapazes de estabilizações definitivas justamente porque o complexo de emoções 
que os sustentam também estão sujeitos a desestruturações, de forma que "o que um afeto comum sustenta, outro afeto comum, contrário e mais potente, pode desfazer". É por isso que "um estruturalismo das paixões é, assim, necessariamente, um estruturalismo dinâmico" (LORDON, 2015, p. 83).

\footnotetext{
Poderíamos, então, responder à pergunta, feita em maio de 1968, sobre se 'são as estruturas que descem às ruas'. A resposta é: primeiramente os corpos individuais desejantes que descem, mas eles só descem por terem sido afetados de certa maneira na e pelas estruturas, isto é, sem paradoxo algum, eles descem para estarem presos às estruturas que o fizeram descer - e porque elas acabaram the parecendo odiosas. (LORDON, 2015, p. 84).
}

Quando aludimos ao conceito de um complexo afetivo-editorial, portanto, estamos nos referindo justamente a uma estruturação de afetos, emoções e desejos, mediada por um veículo jornalístico específico, a partir tanto da validação de afetos presentes em outras estruturações sociais, quanto a partir dos pressupostos intrínsecos de seu projeto editorial e de suas formas de convocação historicamente marcadas. Isso posto, podemos entrever quais eram os termos em jogo no projeto afetivo-editorial da Revista da Semana em sua cobertura política a partir das técnicas de composição comumente utilizadas nas imagens publicadas.

No ano de 1910, das 45 capas que compunham o material jornalístico ${ }^{1}$ e imagético publicado pela Revista da Semana, $80 \%$ era composto por pautas de cunho político e os outros $20 \%$ estavam relacionados ao jornalismo comemorativo - $44 \%$ dele relacionado a algum evento militar. Do conteúdo político, a grande maioria, $76 \%$, era composta por caricaturas. O restante era composto por retratos ou gravuras de políticos - o que figurava como certo colunismo social político, pois apresentava o rosto das personalidades que frequentavam os círculos do poder.

Há, ainda, alguns dados interessantes que podem ser derivados aqui. No que concerne aos personagens que habitavam essas imagens, os homens figuravam a maioria das capas (fortalecendo uma característica composicional já presente no período anterior). Do total de capas, $87 \%$ continham homens e apenas $13 \%$ mulheres. Ainda no que se refere a isso, as mulheres presentes na capa eram de uma natureza imagética bastante específica: nenhuma delas representava pessoas identificáveis

\footnotetext{
${ }^{1}$ Foram excluídas da pesquisa as capas que não continham material de cunho jornalístico.

INTERIN, v. 22, n. 2, jul./dez. 2017. ISSN: 1980-5276. 
pelo nome, mas sim, processos e metaforizações da política como "a câmara" ou "a política" em si.

Os homens retratados, por sua vez, embora aparecessem muitas vezes como metaforizações de processos e instâncias políticas, não estavam restritos a esse tipo de representação: em 40\% das capas trata-se de personalidades que podem ser identificadas pelo nome e em $60 \%$ verifica-se a representação de processos ou instâncias. A disparidade entre homens e mulheres pode ser justificada pelo isolamento feminino das esferas políticas mais amplas (nem o voto das mulheres era ainda permitido), em um projeto editorial que privilegiava um campo que era ocupado, exclusivamente, por homens. A exclusão das mulheres da esfera política, nesse ponto, pode ser observada graficamente na Revista da Semana.

Além disso, em $68 \%$ das capas, as personalidades retratadas aparecem sozinhas, em contraste com o observado no início do século. Nesse período, portanto, o projeto editorial da publicação estava mais interessado nas personalidades políticas do que nas relações e laços estabelecidos entre elas.

No que diz respeito às técnicas de composição mais comumente utilizadas, alguns traços são recorrentes: há a predominância dos planos gerais, em 59\% das capas, e médios, em 30\% delas. Há a introdução de alguns closes também, ausentes no período anterior, em $11 \%$ delas. $\mathrm{O}$ ângulo reto também é utilizado em todas as composições e o equilíbrio estático predomina em relação ao dinâmico - em $70 \%$ das capas.

Aqui, é importante pontuar que a predominância do plano geral conota que o projeto editorial da revista não estava tão interessado no personagem político isoladamente, mas sim, na inserção do personagem em uma relação contextual mais ampla - ou seja, em interação com o cenário e com o contexto expandido. O uso predominante do ângulo reto e do equilíbrio estático conotam seriedade e dureza na composição da imagem.

A caricatura política e o colunismo social se imbricavam na Revista da Semana a partir do compartilhamento da celebração de valores comuns, conforme discutiremos a seguir. Embora a política fosse o assunto predominante nas capas nesse período, o colunismo social mantinha-se como temática central das páginas 
internas, em uma simbiose entre crítica política e educação moral no projeto afetivoeditorial urdido pela publicação nesse período.

\section{Uma estrutura de afetos compartilhados}

A caricatura na Revista da Semana segue uma tradição já presente na imprensa brasileira desde o século anterior. Embora a caricatura e a charge política tenham sua origem, de acordo com a historiografia da área, no século XVII, na Itália, a partir do século XIX, no Brasil, já é possível observar todas as características próprias que compõem o universo conceitual da linguagem caricatural ainda hoje presentes no gênero. O termo caricatura deriva-se justamente da ideia de carregar, que "tem o sentido de exagerar, de ressaltar determinadas características do retratado, sempre com intenção crítica e zombeteira. Significa fazer carga contra alguém, ou seja, atacar. A versão francesa do conceito, charge, expressa com mais nitidez essa ideia: carga" (MOTTA, 2006, p. 15).

As primeiras caricaturas brasileiras disponibilizadas para o grande público datam de 1830, especialmente ligadas ao nome de Araújo Porto Alegre (MOTTA, 2006). Nesse momento, já é possível observar algumas características distintivas do gênero, como o alcance popular e abrangente dado pela composição de desenhos compreensíveis para o grande público, feitos a partir de técnicas como a evocação a metáforas simples e arquétipos tradicionais. Observa-se também a tradução de acontecimentos e personagens políticos em imagens simples e cômicas, com a transposição de conceitos abstratos para soluções imagéticas de alcance popular. Assim, a caricatura, para Motta (2006, p. 18), “contribui para desmistificar e dessacralizar o poder, mostrando líderes e chefes de estado como seres humanos falíveis e, eventualmente, ridículos. Ao mesmo tempo, torna os assuntos políticos menos misteriosos e mais próximos do universo de compreensão do público".

Para Motta (2006), a incorporação do gênero caricatural e da charge política na imprensa é uma das evidências de sua forte raiz popular. Se, no início, as sátiras políticas gráficas eram impressas em folhas unitárias e oferecidas ao grande público, especialmente, por vendedores ambulantes, a grande procura por tais produções fez 
com que elas fossem incorporadas pelos periódicos logo na primeira metade do século XIX, muitas vezes, com publicações especialmente dedicadas ao gênero. É a partir de 1844 que elas são incorporadas às publicações, em títulos como Lanterna Mágica, embora seja apenas a partir de 1860, com a fundação de A Semana Ilustrada, que o gênero passe a obter uma relevância mais acentuada. "Efetivamente, a caricatura veio preencher o espaço da comunicação doméstica. Em sua primeira fase (1844-1895) revelou um caráter combativo, e nos melhores casos, uma intensa participação na vida social e política do Segundo Reinado. Marcou uma nova posição do artista em relação à sociedade" (BELLUZZO, 1992, p. 210). A caricatura adaptase ao discurso jornalístico ao funcionar como crônica política, coadunadas às vertentes ideológicas dos veículos. O Diabo Coxo, de Ângelo Agostini, fundado em 1865, destaca-se como o primeiro jornal de caricaturas publicado em São Paulo, consolidando a crítica política e de costumes a partir do humor gráfico. Para Sodré (1999, p. 179), a caricatura chega à imprensa brasileira em um de seus momentos mais difíceis: "trata-se da fase intercalar, em que, vagarosamente, surgem alterações específicas e técnicas, preparando a imprensa dos fins do século, quando os problemas políticos voltam a primeiro plano e empolgam novamente a escassa opinião existente". A caricatura, para ele, surge como um novo impulso de um jornalismo político em um contexto em que os jornais de opinião perdiam a força e eram relegados a um segundo plano.

No início do século XX, a sátira política gráfica brasileira se moderniza. De acordo com Lima (1963, p. 140), há nesse período “o aparecimento quase simultâneo de três artistas que iriam dominar durante quase meio século no campo da sátira gráfica, Raul Pederneiras, o popularíssimo Raul, Calixto Cordeiro (K. Listo) e J. Carlos". Todos eles contribuíram com a Revista da Semana. Assim, "surgindo a pequeno intervalo, os dois primeiros em 1898, e em 1902 o último, forma esses três grandes artistas do traço cômico que realmente nacionalizaram a caricatura brasileira, pelo caráter nitidamente regional no seu sentido mais alto - do que revestia sua arte". Nesse período, a sátira ferina combinada com os ataques pessoais cede espaço a uma caricatura mais reflexiva (MIANI, 2012).

Sobre a valorização da sátira política na Revista da Semana, é possível dizer que ela se imbuía de um forte caráter moral, relacionado à valorização de um ideal de 
sociedade e de uma escala de valores determinada que, muitas vezes, se afirma pela sua negação. Tal caráter moral, contudo, se mostra menos como uma característica específica das produções individuais da Revista da Semana e mais como uma estruturação de gênero, de forma que a escolha de valorizar esse tipo de produção se coaduna a um projeto editorial específico que desenha um universo de consumo.

Para detalharmos tais questões, é necessário considerar que o gênero da caricatura política, para Gombrich (2012, p. 190), possui algumas características importantes. A primeira delas refere-se ao fato de que "a sátira pictórica se apoia nessa oscilação entre a realidade e o sonho, entre o mito e a metáfora, para obter o seu efeito" a partir de um mecanismo que utiliza “'a regressão a serviço do ego', ou seja, uma exploração consciente de um mecanismo inconsciente" a partir da expressão de impulsos hostis. Assim, embora a caricatura não se refira ao ato de ferir fisicamente uma pessoa, busca-se machucar sua persona, ou seja, "sua posição na rede de convenções culturais", "a soma de todos os valores e crenças compartilhadas que garantem a posição de uma pessoa" (GOMBRICH, 2012, p. 193). A caricatura, para Gombrich (2012, p. 193), é mesmo mais um capítulo dos "anais da crueldade humana" que "registraram incontáveis métodos para desonrar uma pessoa, desde o vitorioso que põe o pé sobre o pescoço do derrotado ao ato de leva-lo ao local de execução ou ao pelourinho, além de exposições semelhantes ao escárnio e à desgraça públicos" a partir do acionamento de uma rede de valores imaginários. A eficácia da produção do escárnio em uma sátira política gráfica, portanto, depende de certo acordo sobre uma escala de valores determinada, sua hierarquização e ativação por meio de um desenho simplificado. Não há, portanto, caricatura que funcione fora de um universo moral desenhado por uma escala de valores acordados socialmente.

É sob esse ponto de vista que é possível dizer que a eficácia de uma caricatura, não apenas depende do acionamento de um sistema de mitos, memórias e metáforas compartilhados socialmente, mas sim, está subordinado a uma predisposição de aceitação do público e, assim como outros rituais sociais, funciona como uma forma de reforço dos vínculos e valores comuns que mantém um grupo de pessoas unido. Ela não é um mecanismo de convencimento, mas sim, de reforço e de mediação dos limites de pertencimento. A predisposição de superioridade do próprio grupo de pertencimento em relação a outros é um dos mecanismos básicos do 
deboche, de forma que "a sátira pictórica tem contribuído para essa noção bastante tola de superioridade ao reforçar o estereótipo que determinado grupo tem de si mesmo e dos demais" (GOMBRICH, 2012, p. 196). A caricatura, assim, não apenas remete a uma escala de valores, como também (e, talvez, principalmente), atua no reforço dos valores de grupo, evocando premissas elogiosas para o grupo de pertencimento e, complementarmente, expondo valores negativos para o considerado o outro. Na caricatura, o deboche e a depreciação do outro servem como uma forma de autovalorização do próprio grupo e da estruturação de valores que esse grupo se auto atribui.

Quando associada ao jornalismo e à crônica política, deriva-se dessa característica o fato de que a sátira política pictórica tem muito pouco poder de convencimento, de forma que a sua função é menos argumentativa do que de síntese. De acordo com Gombrich (2012), ela funciona como uma metáfora para comentar os tópicos do dia, de forma que "ela se baseia em um público que aprecia a astúcia da comparação que não consegue explicar uma situação, mas a resume" (GOMBRICH, 2012, p. 198). É nesse sentido que "o mais característico", portanto, "da sátira pictórica é seu conservadorismo, ou seja, a tendência de se basear no velho estoque de motivos e estereótipos". E, assim, "esses motivos podem ocupar o lugar do mito comunitário, servindo para nos reassegurar a forma de uma explicação" (GOMBRICH, 2012, p. 199).

A sátira política pictórica, nesse sentido, se direciona muito pouco para aquele que é objeto do deboche, estando direcionada para a exaltação dos valores e preconcepções daqueles que a consomem. "Em geral, para o sátiro político, é mais importante lisonjear o público, não incitar o ódio. A receita do sucesso é (...) infle seus egos, confirme seus preconceitos e, acima de tudo, diga-lhes para não se preocuparem" (GOMBRICH, 2012, p. 209). Para resumir a ideia, Gombrich evoca a resposta dada pelo cartunista Nicholas Garland, em uma entrevista para o The Independent, no final da década de 1980:

Nunca, jamais, penso nos cartuns políticos como uma maneira de influenciar pessoas... Acho que eles fazem outra coisa. Os cartuns dos quais me recordo mais são aqueles que, muito sucintamente, expressam algo que eu já sabia, mas de um modo que me é bastante acessível (...) [O cartum] simplifica questões políticas normalmente muito complicadas em imagens fáceis e até infantis. Ele cria um pequeno mundo onde todos os

INTERIN, v. 22, n. 2, jul./dez. 2017. ISSN: 1980-5276. 
tipos de questões que nos afetam de maneira bastante séria podem ser reexaminados. Às vezes tem o efeito de diminuir nossa ansiedade em relação a elas (...). (GOMBRICH, 2012, p. 210).

A sátira gráfica política na Revista da Semana, nesse período, atende justamente à reafirmação de valores de grupo, ao condenar as más práticas políticas, estabelecendo uma hierarquia de ações condenáveis, condensadas em uma imagem de fácil entendimento. As caricaturas estão a serviço de uma educação moral própria à época, que aponta o dedo para as más práticas. Ao privilegiar a caricatura em seu projeto editorial, nessa fase, a Revista da Semana compõe um complexo editorialafetivo a partir do qual os valores de seus supostos consumidores são celebrados e ratificados, evocando mecanismos de identificação mais amplos ao homologar valores comuns e uma moral política comumente aceita.

Ao observarmos os temas mais recorrentemente abordados nessas charges, é possível delinear um complexo afetivo de práticas condenáveis. A dissociação dos sentimentos evocados da imediaticidade e efemeridade das pautas tratadas revela certos conjuntos de sentimentos negativos que são constantemente abordados. A crítica ao ato de enganar os outros é o tema mais recorrentemente reportado nos desenhos, com uma incidência de $36 \%$ do total das charges do período. Ela está especialmente direcionada aos políticos e abarca desde fraudes eleitorais até o ludibriamento do outro nas negociações da política internacional. O uso de expedientes políticos para a trapaça é, portanto, um eixo central das narrativas afetivas engendradas pela Revista da Semana e une seus consumidores tanto em torno da crítica desse tipo de comportamento quanto em termos da imagem que é feita da política brasileira no período.

Seguido a isso, a crítica mais comumente posta nos desenhos está direcionada aos excessos cometidos pelos políticos (com 20\% das incidências), o que se manifesta em um uso massivo de hipérboles nos traços. A ira descomedida, a exaltação e o furor são, portanto, comportamentos também tidos como indesejáveis pela revista. Em terceiro lugar, há a crítica ao uso da máquina pública para a obtenção de benefícios pessoais, em 18\% das charges. Outras articulações afetivas importantes nos desenhos referem-se à ganância dos políticos (tema de 10\% das charges), à morosidade de suas ações ( 8,1 das incidências) e a falta de inteligência em alguns de seus atos $(6 \%)$.

INTERIN, v. 22, n. 2, jul./dez. 2017. ISSN: 1980-5276. 
Tais recorrências, portanto, indicam não apenas uma reincidência temática, mas sim, a estruturação de um repertório de afetos condenáveis historicamente marcado. Tais afetos mediam uma imagem de sociedade compartilhada e facilmente identificável por meio de traçados estereotipados.

É nesse sentido que a sátira pictórica política e o colunismo social da Revista da Semana estavam, nesse período, a serviço de um mesmo projeto-editorial-moral. Se a exaltação dos valores de grupo conhece a sua face negativa por meio do escárnio na sátira política, a sua face positiva se dará por meio de uma cobertura da alta sociedade ligada ao colunismo social.

O espaço para o colunismo social ganha prevalência no conteúdo interno da publicação. Em edições sorteadas do ano de 1910 é possível observar isso de maneira clara. Na edição de 23 de janeiro, as pautas jornalísticas diziam respeito a um perfil de Joaquim Nabuco, à cobertura de festivais artísticos e da agenda cultural, o acompanhamento dos membros da colônia portuguesa que estavam em um cruzador português ancorado no Rio de Janeiro (acompanhado de uma reportagem sobre a tripulação de outros navios), uma reportagem sobre um congresso de irrigação nos EUA com a presença de brasileiros, um perfil da família Baeta Neves, um perfil do $4^{\mathrm{o}}$ Posto de Socorros Policiais, a cobertura de uma festa de um grupo de alunos do Externato Gonçalves e de outras escolas de elite, uma reportagem sobre moda para mulheres, os falecimentos da semana e movimentação artística e esportiva dos clubes mais proeminentes. $\mathrm{O}$ direcionamento desses assuntos enquadrava-se nos parâmetros mais amplos do colunismo social, com especial atenção para o comportamento, ação e curiosidades sobre as pessoas envolvidas. Trata-se de uma estrutura de elaboração de pautas que irá permanecer, ao longo do período, nas outras edições da revista. A cobertura do dia a dia de alguns espaços de elite - como os principais colégios, clubes e teatros - é exaustivamente exposto. Como observa Patroclo et al. (2015), em relação à cobertura do colégio Pedro II na Revista da Semana, estavam presentes "desde as cerimônias de formatura, as festividades cívicas, a eleição da aluna mais bonita ou um almoço dos professores com uma autoridade governamental". Além disso, "também eram dedicados amplos espaços a homenagear e a preservar o passado do Colégio de Pedro II". 
A partir dessas pautas, é possível perceber que o eixo que organiza a estruturação de pautas nas imagens da Revista da Semana no período é, a partir do colunismo social, empreender um elogio às boas práticas. As boas ações eram encontradas pela Revista da Semana nos consultórios médicos, nas escolas, nos clubes esportivos, nas festas da alta sociedade, entre outros espaços. Tal cobertura construía um ethos para a elite brasileira do início do século, exaltando as suas supostas qualidades intrínsecas, em um projeto afetivo-editorial que colocava a educação moral como ponto nodal de sua estruturação.

De fato, a revista era a face mais visível de um Brasil cuja construção da imagem de si estava toda voltada para o progresso, de forma que a revista insistia na veiculação dos ícones da modernidade. A denúncia e a preocupação social, embora já de longa data fizessem parte das preocupações centrais da imprensa brasileira, eram temáticas reservadas aos jornais que faziam delas as suas matérias-primas. De fato, a Revista da Semana deve ser inserida dentro do contexto da ecologia informativa de sua época que, desde o final do século XIX, estipulava uma divisão de trabalho bastante clara entre os jornais e as revistas que delimitava, de uma maneira geral, os programas dos periódicos. Se aos jornais cabia a crítica política propriamente dita, as revistas participavam de uma educação moral para mediação de afetos políticos.

Des Hons (1987, p. 27) descreve essa primeira geração de revistas brasileiras como publicações que visavam espelhar o que de mais distinto havia na sociedade. "Mesmo que estas revistas fossem endereçadas a um público variado, que incluía a burguesia e a classe média, elas ainda eram impregnadas pelo elitismo cultural, marca da imprensa do século XIX". E, assim, "esses magazines indicavam tudo o que se devia saber para fazer parte da 'boa sociedade"”.

É a partir dessa ordem de coisas que Martins (2001, p. 127) comenta que as publicações desse período “consolidaram representações propagadoras dos valores do novo regime, quando o espetáculo republicano ocupou as páginas higienizadas daquele periodismo". Suas imagens "confirmavam a utopia da Ordem e do Progresso configurada nas paradas militares e recepções a políticos ilustres, em cenas valorizadas pela arquitetura monumental que brotava na placidez das praças e jardins e na pujança da indústria ao retratar suas instalações e maquinário modernos". O 
político, nessas publicações, “completavam o 'passar em revista' de uma cidade que desfilava sua prosperidade".

O autoelogio das elites, nesse caso, exerce um papel moralizador na Revista da Semana, como uma espécie de manual das boas práticas e da boa educação, em um projeto afetivo-editorial que combina a exibição dos valores negativos a partir da sátira pictórica política e a exibição dos valores positivos a partir do colunismo social. São esses os elementos centrais que compõem o pathos político da revista, articulado a partir da estruturação de um conjunto de afetos mediados que preenchia o signo vazio da política, conforme esmiuçaremos a seguir.

\section{Considerações Finais: a política como signo vazio preenchido por imagens afetivas}

A partir das características analisadas anteriormente, é possível dizer que, em relação às práticas de consumo da política que a imagética da Revista da Semana urdia, estava pressuposto a articulação de um certo "hábito hermenêutico" (LORDON, 2015) de preenchimento para o signo vazio da "política".

A partir da consideração, esmiuçada anteriormente, de que os afetos se organizam de acordo com estruturações sociais que são mediadas e reproduzidas pelas instituições de diversas ordens, Lordon (2015, p. 70) irá elaborar a noção de hábito hermenêutico, explicando um conjunto de pensamentos, associações e ajuntamentos simbólicos comuns, presente em um determinado grupo em um momento histórico preciso a partir da evocação de um campo afetivo. A partir do pressuposto espinosiano de que "com efeito, um soldado, por exemplo, ao ver os rastros de um cavalo sobre a areia, passará imediatamente do pensamento do cavalo para o pensamento do cavaleiro e, depois, para o pensamento da guerra etc." ao passo que "já um agricultor passará do pensamento do cavalo para o pensamento do arado do campo", Lordon irá afirmar que os grupos possuem constantes interpretativas (hábitos) que coordenam as ligações simbólicas em direções similares. Um hábito hermenêutico, portanto, é 
uma estrutura estratificada de esquemas concatenadores orientados, dos quais uma parte é comum em grande escala - todo mundo, por exemplo, associa o barulho do trovão à iminência da chuva -, uma parte é comum na escala de grupos mais restritos - as associações dos camponeses são as mesmas, mas diferem daquelas dos soldados -, uma parte mais idiossincrática, formada, por exemplo, de acordo com as fixações neuróticas de uma história pessoal. (LORDON, 2015, p. 71).

É nesse sentido que experiências ou afecções em comum determinam redes simbólicas similares, produzindo associações de sentido e concatenações comuns - o que Lordon (2015) entende por hábitos hermenêuticos comuns. Ainda sobre isso, o autor pondera que

\begin{abstract}
se, por exemplo, as condições de existência material entram, para grande parte das pessoas, nas experiências vividas cotidianamente, então, a homogeneidade por grupos sociais dessas afecções vinculadas à vida material determina uma homegeneidade correspondente das ligações de ideias, portanto, das atribuições de sentido e das valorizações que as sucedem - e os 'hábitos', consequentemente, estruturam-se, para uma parte das pessoas, sob uma base de classe. (LORDON, 2015, p. 71).
\end{abstract}

Posto que o signo da política tem um significado múltiplo e flutuante, as imagens, na Revista da Semana, funcionavam como suportes materiais dos afetos que dão conteúdo ao campo dos possíveis sobre o que o termo poderia significar. Ao tratar da questão sobre como as imagens são capazes de condensar estados afetivos, Didi-Huberman (2016) chama a atenção para o fato de que, durante muito tempo, as emoções foram utilizadas pela filosofia apenas a partir de sua conotação negativa. Ele lembra que, em Aristóteles, por exemplo, a palavra pathos é deduzida a partir daquilo que, em gramática, é chamado de a voz passiva do verbo. " $E u$ corto, eu queimo' ilustra a voz ativa ou em ação”, ao passo que “"eu sou cortado', 'eu sou queimado' ilustra a voz passiva ou em passividade, ou seja, em patos'”. O exemplo é interessante "pois se refere tanto a uma dor injusta, à tortura, por exemplo, como a uma dor benéfica, como quando o médico corta um tumor ou cauteriza uma ferida, queimando-a" (DIDI-HUBERMAN, 2016, p. 20). A paixão e os afetos, portanto, foram muitas vezes ligados à passividade, à impossibilidade de ação ou, em um outro aspecto, como um elemento contrário à razão.

A emoção seria assim um impasse: impasse da linguagem (emocionado, fico mudo, não consigo achar as palavras); impasse do pensamento (emocionado, perco todas as referências); impasse de ação (emocionado,

INTERIN, v. 22, n. 2, jul./dez. 2017. ISSN: 1980-5276. 
fico de braços moles, incapaz de me mexer, como se uma serpente me imobilizasse). (DIDI-HUBERMAN, 2016, p. 21).

O fim da oposição entre emoção, de um lado, e razão e ação, de outro, na filosofia, se dará a partir do entendimento de que a vida sensível pode ser descrita a partir de sua energia passional, de forma que os afetos passam a ser encarados como gestos ativos, primeiramente a partir de Nietzsche e Bergson, com ecos em Freud, Merleau-Ponty e Sartre. Assim, "uma emoção não seria uma e-moção, quer dizer, uma moção, um movimento que consiste em nos pôr para fora (e-, ex) de nós mesmos?" (DIDI-HUBERMAN, 2016, p. 25). A emoção, então, passa a ser vista como um tipo de ação - ação esta que é ao mesmo tempo interior e exterior ao indivíduo.

Interior na medida em que os sentimentos sempre afetam a um sujeito que os vivencia como experiência. Exterior, contudo, na medida em que "a emoção não diz eu", ou seja, ela se manifesta a partir de gestos que são exteriores ao indivíduo, fazem parte de uma memória coletiva e se reproduzem nele. Há, a partir disso, uma espécie de "expressão obrigatória dos sentimentos", que é culturalmente codificada e remete aos gestos de manifestação de emoções, esperados nos grandes ritos públicos, por exemplo. "Trata-se de emoções verdadeiras, mas elas passam, elas precisam passar, por sinais corporais - gestos - reconhecíveis por todos" (DIDIHUBERMAN, 2016, p. 33), estabelecendo uma linguagem passional.

Se voltarmos à questão da imagem, veremos que as fotografias e gravuras "são como cristais que concentram muitas coisas, em particular esses gestos muito antigos, essas expressões coletivas das emoções que atravessam a história”. E, assim, "é como se a história das artes visuais - a pintura e a escultura, mas também a fotografia - pudesse ser lida como uma imensa história das emoções figuradas, dos gestos emotivos que Warburg denominava "fórmulas patéticas"” (DIDIHUBERMAN, 2016, p. 35).

As fórmulas patéticas (Pathosformel) dizem respeito à "intricação indissolúvel de uma carga afetiva e uma fórmula iconográfica" (DIDI-HUBERMAN, 2013, p. 174). Tal fórmula iconográfica é um rebatimento de uma série de sedimentações e rearticulações de uma memória coletiva e, por esse motivo, DidiHuberman entende-as como fósseis em movimento, como um convite à ação. A 
expressão "formas do pathos na imagem" (pathosformel), portanto, remete à ideia de um "traço significante, um traçado em ato das imagens (...), algo pelo qual ou por onde a imagem pulsa, move-se, debate-se na polaridade das coisas". Remete, ainda, ao "combate de todos os instantes com a complexidade fervilhante das coisas do espaço e com a complexidade intervalar das coisas no tempo" (DIDI-HUBERMAN, 2013, p. 173).

As imagens da política na Revista da Semana podem ser entendidas como manifestações das fórmulas do pathos, ao empreender a união de uma carga afetiva com uma fórmula iconográfica que se expressa na concorrência de tempos heterogêneos, ligados à memória coletiva e às suas diversas reconfigurações, em uma mesma imagem. A articulação de estereótipos de fácil entendimento, nas charges, e de valores socialmente mediados, nas colunas sociais, compõem um projeto afetivoeditorial que mediam entendimentos específicos acerca da política do período, preenchendo o campo dos possíveis discursivos que o termo pode abarcar a partir da evocação de um conjunto de afetos, embasado em valores morais, historicamente marcados.

\section{REFERÊNCIAS}

BELLUZZO, Ana Maria de Moraes. Voltolino e as raízes do modernismo. São Paulo: Marco Zero, 1992.

DES HONS, Andre de Seguin. Le Brésil, presse et histoire 1930-1985. Paris:

L'Harmattan, 1987.

DIDI-HUBERMAN, Georges. A imagem sobrevivente. Rio de Janeiro: Contraponto, 2013.

DIDI-HUBERMAN, Georges. Que emoção! Que emoção? São Paulo: Editora 34, 2016.

GOMBRICH, Ernest. Os usos das imagens. Porto Alegre: Bookman, 2012.

LIMA, Herman. História da caricatura no Brasil. Rio de Janeiro: José Olympio, 1963. 
LORDON, Frédéric. A sociedade dos afetos: por um estruturalismo das paixões. Campinas: Papirus, 2015.

MARTINS, Ana Luiza. Revistas em Revista: imprensa e práticas culturais em tempos de república, São Paulo (1890-1922). São Paulo: Edusp, 2001.

MIANI, Rozinaldo Antonio. Charge: uma prática discursiva e ideológica. Nona Arte, v. 1, n. 1, 2012, p. 37-48.

MOTTA, Rodrigo Patto Sá. Jango e o golpe de 1964 na caricatura. Rio de Janeiro: Jorge Zahar, 2006.

PATROCLO, Luciana Borges et al. Verdadeiras glórias nacionais: a memória acerca das primeiras gerações de professores do Colégio de Pedro II através das páginas da Revista da Semana. Revista Brasileira de História da Educação, v. 15, n. 3, p. 173-200, setembro/dezembro 2015.

SAFATLE, Vladimir. O circuito dos afetos: corpos políticos, desamparo e o fim do indivíduo. Belo Horizonte: Autêntica, 2016.

SODRÉ, Nelson Werneck. História da imprensa no Brasil. Rio de Janeiro: Mauad, 1999.

Recebido em: 23.02.2017

Aceito em: 30.05.2017 